\title{
Greek Ontology and the 'Is' of Truth MOHAN MATTHEN
}

This is an essay about the ontological presuppositions of a certain use of 'is' in Greek philosophy - I shall describe it in the first part and present a hypothesis about its semantics in the second.

I believe that my study has more than esoteric interest. First, it provides an alternative semantic account of what Charles Kahn has called the 'is' of truth, thereby shedding light on a number of issues in Greek ontology, including an Eleatic paradox of change and Aristotle's response to it. Second, it finds in the semantics of Greek a basis for admitting what have been called 'non-substantial individuals' or 'immanent characters' into accounts of Greek ontology. Third, it yields an interpretation of Aristotle's talk of 'unities' which is crucial to his treatment of substance in the central books of the Metaphysics.

\section{A COMPREHENSIVE USE OF ABSOLUTE 'IS' I.1 Some Examples}

There is a use of 'is' in Greek philosophy that comprehends both the idea expressed by our 'is' of existence (whether or not that marks a separate use of 'is' in Greek) and that expressed by the copula. For example, Aristotle sometimes states the Principle of NonContradiction in this way: "It is impossible for the same thing both to be and not to be". It is obvious from the generality of this principle that even though the use of 'is' it contains is absolute (and would thus normally be identified as denoting existence), it is meant to comprehend both existential and predicative states of affairs - that is, it prohibits a thing existing as well as not existing, and equally it prohibits a thing being both $\mathrm{F}$ and not- $\mathrm{F}$ for any value of ' $\mathrm{F}$ '.1 (Similarly for Plato's category of things "that are and are not" - Republic 478 de - these are things that both exist and fail to exist, that are F as well as not-F.)

There are many other examples of this use of 'is'. Thus consider the generality of Plato's and Aristotle's definition of falsity (and of Aristotle's corresponding definition of truth): To say that what is is not and what is not is is false. (See Sophist, 240 de and Met, 1011 b 26-27). Again, there is Aristotle's statement at De Interpretatione 19 a 23: 'What is necessarily is when it is; and what is not necessarily is not when it is not' etc. This is supposed to cover not only existential situations like that alluded to in 'There will be a sea-battle tomorrow', but also situations that Aristotle himself characterizes predicatively, as in 'This coat will be cut up'. From an earlier period there is Protagoras' famous dictum: 'Man is the measure of all things, of what is that it is, of what is not that it is not'. Obviously this applies to what is absolutely, but as Plato understood it in the Theaetetus, it also applies to whether the wind is cold, or whether the wine is bitter.

\subsection{How Not To Treat These Examples}


The occurrences of 'is' above cannot easily be assimilated to any of the more familiar uses of 'is'. For example, they cannot be treated as instances of the so-called 'incomplete copula' 2 because the principles in which they occur range also over existential situations best described in terms of absolute 'is'.3 Conversely, they cannot (given the normally accepted existent objects, individual substances and properties) be treated as involving the 'is' of existence because this would leave out predicative states of affairs.

It might be thought that a good way to describe our use of 'is' is as a kind of schematic variable, that is as standing for no one notion, but doing double duty for two or more different notions, standing for whichever is most appropriate at a given moment. Thus one might be inclined to say something like this: "When Plato says that sensible things both are and are not, he means both that they exist and do not exist as well as that they are $F$ and not $F$ for at least some values of ' $F$ '."

Useful though such a periphrasis might be as a reminder of the range of the quantifiers that might govern occurrences of our 'is', for example in the principle of noncontradiction, it is clearly inadequate as a theory of how 'is' comes to be used in this way. After all, it sounds grammatically unacceptable to abbreviate 'is F' by 'is' (except in the limited range of cases mentioned in note 2), and so we need to explain how philosophers so diverse in time and style as Protagoras, Plato and Aristotle came to use so opaque a stylistic device.

The problem becomes particularly acute when we notice that there are times when these philosophers seem to treat comprehensive uses of 'is' as standing for a unitary notion. Three important examples of this may be mentioned here. Plato slides, as Kahn has noticed, 4 between two formulations of the eternality of Forms - he says, with no indication that these are different, both that something is eternally $F$ and that the F-itself is eternally. In a similar vein, Aristotle puts his theory of categories in different ways, saying sometimes that 'is' is said in many ways ( $E N, 1096$ a 23), sometimes that the categories are "figures of predication" (Met, 1017 a 23), and in yet other places that the categories are kinds of the things-that-are (Cat, I b 25: note that onta embodies an absolute construction of einai). It is as if Aristotle does not distinguish here between the claims that there are many sorts of 'is $\mathrm{F}$ ' constructions, that there are many sorts of existence, and that there are many uses of the verb 'to be'. Finally, we should note an unusually explicit use of the 'An F is'/'Something is F' transformation. In describing Protagorean relativism in the Theaetetus (156 ff.), Plato describes a theory of perception in which a perceiver and a thing perceived come together, thereby begetting "twins", one of which is a sensation and the other is something described, for example, as a whiteness (156 d), a sweetness (159 d) or a bitterness (159 e). The result of this birth is that the passive parent, the thing perceived, comes to be characterized by the corresponding adjective - that is, it becomes white, or sweet, or bitter. "The object that joined in begetting the colour is filled with whiteness and becomes in its turn, not whiteness but white, whether it be stick or stone" (56e; cf. 159 de). Here an equivalence is established between '(An) F-ness comes to be' and 'Something comes to be F'.5 
All these philosophers (I am assuming that Protagoras was accurately represented by Plato, but if this is false read 'Plato's Protagoras' for 'Protagoras') were making, in the examples cited, claims in the theory of Being: Plato is interested in establishing that Forms (as contrasted with sensibles) are things-that-are (not thingsthat-are-and-are-not), Aristotle in showing that there is not just one kind of Being, and Protagoras in showing that Being is measured by men. But Being here comprehends, as we have seen, both the existential and the predicative, and the formulation of these claims displays a strange ambivalence between the 'is' of predication and that of existence 6 - just that ambivalence that we found in our 'is'. This seems to show that Greek philosophers tend to treat our 'is' as unitary, or at least that they treat it as corresponding to some unitary notion of Being. It is thus not merely by place-holding that it acquires its comprehensiveness.

\section{3 A Formal Characterization of Comprehensive 'Is'}

Let us look once again at Aristotle's ontic statement of the principle of non-contradiction (e.g. at Met, 1006 a 4-5).

O: It is impossible for the same thing both to be and not to be.

Evidently (see note 1 ), this principle is meant to be equivalent to a predicative statement:

$\mathrm{P}$ : It is impossible for the same thing both to belong and not to belong to the same thing at the same time (+ some qualifications that do not concern us here: Met, $1005 \mathrm{~b}$ 18).

The condition under which $\mathrm{P}$ and $\mathrm{O}$ are equivalent is:

C 1: For all $x$ and $y$ there is a $z$ such that $x$ belongs to $y$ if and only if $z$ is. 7

Thus Aristotle's use of $\mathrm{O}$ and $\mathrm{P}$ to state the same law implies that he at least implicitly subscribes to $\mathrm{Cl}$.

A similar result can be obtained by scrutinizing Aristotle's definitions of truth and falsity at Metaphysics $1011 \mathrm{~b} 25$ : a judgement is true if it says that what is is or what is not is not, otherwise it is false. By inspecting the definiens and definiendum we derive:

C2: For all propositions, $p$, there is an $x$ such that $p$ is true if and only if $x$ is.

C2 accounts also for the (presumed) equivalence of the ontic statement of noncontradiction above with the alethic statement of the principle at Metaphysics $1011 \mathrm{~b}$ 14.

C I and C2 constitute what I have been calling the comprehensiveness of the 'is' that we are discussing. And C2 is the condition that justifies calling it 'the 'is' of truth'. Our task is to explain why Greek ontologists accepted these principles. 


\section{I.4 Further Evidence and Two Bad Theories}

An interesting application of our "comprehensiveness axioms" comes in connection with change. At De Gen et Corr 316 b 34-317 a 10, 319 b 25-31 and Physics 190 a 10-12, Aristotle maintains that every alteration is accompanied by a perishing and a creation. Suppose, for example, that a man ceases to be artistic. This change in the man is simultaneously accompanied, he says, by a creation of an unartistic and a perishing of an artistic or by the creation of an unartistic man and the perishing of an artistic man. (He does say that these are not creations or perishings in an unqualified sense. This is a point that will concern us later. For the moment we shall be concerned only with why they are creations or generations in any sense.)

This point is presupposed also by Aristotle's characterization of poiesis as concerned with genesis (EN, 1140 a 10). It is evident that Aristotle is here contrasting poiesis, an activity that derives its value from a consequence, with praxis, an activity that has "intrinsic" value (i.e. regardless of what might result from it), and that this distinction has nothing whatever to do with whether some previously non-existent thing is brought into being. For example, medicine involves poiesis, though typically we should not want to say that it brings anything into being; rather it brings a man to health. The point that Aristotle is making is that it is essential topoieseis that they create changed circumstances, for these give them their value. But according to the terminology established in the De Gen et Corr and Physics, any change is accompanied by a genesis; there is no difference between saying that an activity results in changed circumstances, and saying that it is concerned with genesis.

Evidently $\mathrm{Cl}$ and $\mathrm{C} 2$ ground these otherwise puzzling assertions. A creation occurs when something that was not comes to be. An alteration, on the other hand, occurs when something that was not $\mathrm{F}$ comes to be $\mathrm{F}$, or when a false (undated) statement comes to be true. (See Cat, 4 a $22 \mathrm{ff}$.) But according to $C 1$ something is if and only if $x$ is $F$, and according to $C 2$ something is if and only if $p$. Thus if $x$ comes to be $F$, or $p$ comes to be true, something comes to be. And this is the assertion that Aristotle makes.

Interestingly, the De Gen et Corr and Physics passages tell us how to characterize the entity in question: when an $X$ comes to be $F$ we are to say either that an $F X$ comes to be, or simply that an F does. We have encountered two other passages in which the latter transformation occurs: Theaetetus 156 e and 159 de. And it parallels the duality noted between 'Something is $\mathrm{F}$ ' and 'An $\mathrm{F}$ is'. Let us call this the indefinite transformation. It allows us to go from 'Socrates is/becomes $F^{\prime}$ or 'A man is/becomes $F^{\prime}$ to 'An F is/comes-to-be'. The other transformation (observed at De Gen et Corr, $319 \mathrm{~b}$ 25-31) allows us to go from 'An X is/becomes F' to 'An FX is/comes-to-be'. Let us call this the attributive transformation. It is part of our task to explain these phenomena.

The application of comprehensiveness to change represents a perhaps unexpected degree of continuity between Aristotle and his predecessors. Parmenides, for example, had argued (fragment 8, lines 6-8) that creation is impossible, but apparently concluded (for example at line 26 of the same fragment) that all change is 
impossible. This has been diagnosed as fallacious reasoning, as a confusion between two quite distinct uses of 'is', namely the existential and the predicative. And it has also been claimed8 that Parmenides was not confused; rather that he was using a "fused" conception of Being, i.e. one that combines existence and predication. The claim is that in Parmenides' case at least, comprehensiveness is to be explained by (con)fusion.

However, Aristotle cannot be accused of any such confusion, or fusion. In the De Gen et Corr he clearly distinguishes between creation and alter- ation, which can be defined as follows:

$x$ is created $=x$ was not and $x$ is.

$\mathrm{x}$ is altered $=$ For some $\mathrm{F}, \mathrm{x}$ was not $\mathrm{F}$ and $\mathrm{x}$ is $\mathrm{F}$.

These definitions seem to presuppose a clear distinction between absolute and predicative uses of 'is'; and they exploit this distinction in order to formulate the concept of a sort of change, alteration, that permits a con- tinuing subject. It is thus unlikely, to say the least, that a confusion or identification of these uses could be what explains the correlativity of alterations and creations, or Aristotle's commitment to comprehensiveness.

These comments have a consequence for the interpretation of Par-menides. What in his writings forces us to assume that his theory of 'is' is to be blamed for his conclusion that all change is impossible? Suppose that the difference between alteration and the other changes were pointed out to him. Could he not still argue as follows? "I now recognize that alterations are not the same as creations. But every alteration is accompanied by a simultaneous creation (and by a destruction). I have shown that creation is impossible - there is no such thing. So there is no such thing as alteration either." So even if he does confuse or fuse distinct uses of 'is', it will not do for Aristotle or for us to criticize him merely on the grounds of this error. Parmenides is simply employing an inference that Aristotle endorses. Since Aristotle does not think that change is impossible, it must be possible to admit change into the logic of even this 'is'.

The problem then is this: What theory of 'is' permits the distinction between alteration and creation given above, and at the same time allows Aristotle to hold that every alteration is accompanied by a creation? That is, what accounts for $\mathrm{Cl}$ and $\mathrm{C} 2$ above, since these yield the desired result?

Of secondary importance to us is this question: since merely distinguishing between alteration and creation will not help Aristotle evade the Par-menidean conclusion that that change is impossible, how does he evade it?

\section{5 Kahn on the 'Is' of Truth}

Let us look now at the proposal of Charles Kahn.9

Ignoring for present purposes the admirable and useful syntactic sutb- tleties of Kahn's account (most of which I can leave untouched, since I am concerned with semantics), the proposal concerning the semantics of 'is' in philosophical contexts comes to this. The copula has two functions. It joins predicate to subject, and it states of 
the sentence in which it occurs that it (the sentence) is true. Further, there is an "essential ambiguity" in this second function of 'is': it can be taken not only as saying that the sentence in which it occurs is true, but also that the fact "corresponding" to that sentence is-so, or obtains.

It is very important to realize that being-so, or obtaining, as applied to facts is not existence. It is therefore important to distinguish Kahn's pro- posal from one made by Wiggins according to which Plato understood truth applied to sentences as equivalent to existence applied to the corre-sponding facts.10 I find Wiggin's proposal implausible (even as an account of ordinary intuitions) for the following reason. Suppose that 'John is pale' is true, and suppose that it is true precisely because there is a fact, John's being pale. Now suppose that John acquires a tan and is no longer pale. 'John was pale' is now true nevertheless. Is it not plausible to say that the fact that once made 'John is pale' true is the very same as the fact that now makes 'John was pale' true? If so, ceasing to be true does not correspond to going out of existence. It would be more appropriate to say that the fact in question continues to be, but ceases to obtain, or beso. This is precisely what Kahn does say: he is careful to distinguish between being-so and existence.11

We can see how well-measured Kahn's proposal is to accounting for the comprehensiveness axioms. Why is there a thing that is for every true proposition? Because 'is' can mean 'is true', and so to say of a proposition that it is true is to posit a thing-that-is, namely the proposition itself. Why is there a thing-that-is for every property that belongs to an individual? Because there is, for each such pair, a true proposition that asserts that the connection holds.

Still, the proposal is not as simple as it may look. To illustrate this, let us examine the question of how copula modifiers are to be treated. Since Kahn's claim is that a single occurrence of a verb is "overworked" or "overdetermined" - i.e. that it has, simultaneously, two functions - one would imagine that any modifiers would simultaneously affect both functions. But it is easy to see that this cannot be so.

Consider tense. It seems that 'Socrates was sitting' contains a tense modifier on the copula. But we cannot allow this modifier to operate more than once. Our sentence says either that it is true that Socrates was sitting, or that it was true that Socrates is sitting. It certainly does not say that it was true that Socrates was sitting. But how are we non-arbitrarily to read the same verb in two roles at once, but the verb modifier only once? The difficulty extends to negated copulae - these say either that the positive joining of predicate to subject is false, or that the negative joining is true, and obviously not that the negative joining is false.

Kahn could attempt to get out of this difficulty by asserting that the modifiers operate on a sentence as a whole, rather than on the copula. But this is not a tenable theory of tenses in Greek or any other Indo-European language. Nor is there any evidence that Aristotle recognized sentential operators as distinct from copula modifiers. Yet Kahn attributes to Aristotle an explicit awareness of the "veridical nuance" of the copula. (He cites Met 1017 a 31-35 and Book $\Theta$, chapter 10.) Thus it will be difficult for him to deal satisfactorily with Aristotle's theory of the modifiers. 
Secondly, consider Aristotle's definition of truth and Plato's similar definition of falsity: To say that that which is is and that which is not is not is true. Kahn's claim is that these uses of 'is' represent "the veridical construction proper" (Phronesis XXVI, p. 106). Now the veridical construction is, we recall, "*essentially ambigbuous" between 'is true' and 'is-so'. Aristotle could not have been using 'is' in the first of these senses, for then his definition would be trivial and uninformative. So he must consciously have been using the second sense. Can it be plausibly held, though, that Aristotle was this clear about the ambiguity in the veridical construction, and yet made no mention of it, even to warn his readers how he was using 'is'? I think not.

Finally, Kahn is robbed of the ability to treat of the Eleatic paradox of change by assimilating it to that of negative existentials. He is of course aware of this, and has an article defending the view that Parmenides depended instead on the "factive" nature of 'knows'.12 It is not my intention directly to take issue with Kahn's interpretation of Parmenides. But it is relevant to note that Parmenides was reported by some of the ancients in a way that does not support Kahn's thesis. For example, Plato has the Eleatic Stranger in the Sophist report the views of 'my father Parmenides' in a way completely independent of knowledge (he uses other psycho- logical attitudes, believing and saying), and explicitly tied to the problem of negating being. Let us waive the question of who is right about Parmenides, Kahn or Plato. The question is: What account is Kahn to give of the substantial degree of credence that Plato obviously gives to the argument he reports?

These objections show, at most, that the application of Kahn's proposal to certain ancient texts is not unproblematic. There is, however, another more conclusive objection to his proposal. It is that 'is true' and the copula are grammatically incongruent. The former attaches, typically, to nominalizations of sentences or to phrases, such as 'Pythagoras' theorem', that allude to sententially complete utterances.13 The latter, by contrast, plays an essential role in sentence formation, in the welding together of sub-sentential parts. I want now to argue that Aristotle was explicitly aware of this feature of the copula, and makes it an essential part of his account of being. My account of Aristotle's philosophical grammar will yield an explanation of the comprehensiveness phenomena described above, and sheds light on the other issues mentioned in the opening section of the present essay.

\section{ARISTOTLE ON THE SYNTAX AND SEMANTICS OF 'IS' II. 1 'Is' as Dyadic: De Interpretatione, 1-4}

In De Interpretatione 1-3, Aristotle distinguishes between nouns and verbs. Both are significant (semantikos), he says, but nouns signify, whereas verbs signify about. Moreover nouns do not carry tense, whereas verbs do.14

Now, 'is' carries tense, and in this respect it is like a verb. However, it is made clear that in other respects it is not like a verb. First, it is not significant, as verbs are, but only consignificant: "By itself it is nothing, but it consignifies some combination which cannot be thought of without the components" (16 b 24-26). Secondly, it is required in any whole sentence. "Falsity and truth have to do with combination and separation. 
Thus names and verbs by themselves - for instance 'man' or 'white' 15 when nothing further is added - are like thoughts that are without combination or separation" (16 a 12-14).

The argument seems to be this: 'Is' consignifies "some combination" (and 'is not' signifies separation?). Truth-bearers require combination or separation. Therefore truth-bearers require 'is" or 'is not' (or some equivalent).

Let us call a use of 'is' monadic if it must be completed by exactly one term to form a sentence, dyadic if it requires exactly two. Aristotle's remarks suggest (a) that the copula is dyadic, and (b) that a subject- predicate sentence will incorporate a noun (the subject), a verb (since the predicate will signify-about the denotatum of the subject) and a copula (or equivalent) to "combine" or "separate" these.

At first sight this seems a bad theory. For copulae are required, it would seem, exactly where other verbs are absent. For if we have a finite verb like 'runs' we can form a sentence without the courtesy of a copula, e.g. 'The man runs'. However, a wider examination of the texts provides us with an Aristotelian response to this. 'The man runs' is equivalent, he thinks, to 'The man is running' where 'running' is the participle functioning as an adjective, and 'is' is the copula. (See De Int, 21 b 9; Met, 1017 a 28 and 1028 a 15; Phys, 185 b 27.)

Here then is one plausible account of Aristotle's theory of the subject- predicate sentence:

(a) It consists in the first instance of two parts - a noun and a verb phrase. The noun carries no tense and signifies the subject; the verb phrase carries tense and signifiesabout the ontological subject.

(b) The verb phrase can be split up into two functional (as opposed to syntactic) parts. It instantiates the paradigm:

Copula equivalent + predicable denoter.

This is not a grammatical but a semantic observation, for sometimes the functional parts will not correspond to syntactic parts. For example, 'runs' (a verb phrase) cannot be syntactically broken up in conformity with the paradigm, but is semantically congruent with 'is running'. On the other hand, 'is running' and 'is white' are both syntactically and semantically instances of the paradigm.

This theory improves on Plato's Sophist (26 le-263d) grammar in at least two ways. Plato had held that there are two parts of speech, nouns and verbs, both of which reveal being (26 1e-262a), and that a combination of one of each sort constitutes a statement. By making the role of the copula- equivalent separate from that of nouns and verbs, Aristotle is able to account for adjectival predications such as 'The man is white'. Secondly, he is able to account for the difference between 'the running man' and 'The man runs', both of which are combinations of noun and verb, but only one of which expresses a statement. The difference, according to Aristotle, is that only the complete sentence contains the copula equivalent - the other phrase has the same noun and predicable-denoter, but lacks anything that consignifies Being.16 
(c) Unfortunately for the clarity of both his exposition and his own thought, Aristotle uses the term 'verb' (rhema) to denote both the verb phrase taken as a whole, and the predicable-denoter by itself. He presum- ably intends it to mean 'verb phrase' - he says 'a verb is what consignifies time' (16 b 6), that verbs are inflected (16 b 16) and that verbs signify- about. On the other hand, he probably has predicable-denoters in mind when he says (16 b 19) "When uttered by itself a verb is a noun and signifies something"," 7 the point being that predicable-denoters stand to predi- cables in just the way that nouns stand to what they denote.18 Thus a predicable-denoter requires 'is' before it can be adjoined to a noun to yield a sentence. (This explains 17 a 10-11, which has been taken as evidence that 'is' is a verb.)

The theory that I have presented makes Aristotle absolutely clear and explicit on the role and type of 'is': the copula links sub-sentential denoting expressions, converting these into sentences. There would seem to be no role here for the sentential operator role that Kahn envisages.19 Kahn may wish to respond by saying that it is Aristotle's intention here to deal with only one of the two functions of the copula, reserving for Metaphysics r, 1017 a 31-35, E 4, and e 10 a discussion of the veridical nuance. I shall return to these passages later, after I have discussed why no such ambiguity is required to account for the facts.

\section{II.2 'Is' as Monadic: Another Look at De Interpretatione 1-4}

Revealing though the above account is about Aristotle's philosophical grammar, I do not think it tells the whole story. One indication of this is that nowhere in the De Interpretatione does Aristotle explicitly mention dyadic 'is', although he does mention monadic 'is'. (I am indebted to David Hitchcock for this observation, which seems to have been neglected by every commentator on that work.) Thus he says thrice (16 a 919, 16 b 19-26, and 16 b 28-29) that both nouns and verbs need to be supplemented by 'is', but can we conclude that 'Man running' is similarly lacking an 'is'? Aristotle's claim seems to be that each noun and each verb is lacking consignification of being and this permits us to conclude that there is a need for a monadic use of 'is' - thus 'Man is' and 'Running is' are sentences 20- but where does he say that there is a dyadic use of 'is' to complete 'Man running'? It is difficult to adapt Aristotle's remarks about 'is' in the first four chapters of the work to dyadic 'is'.

But how can Aristotle manage without a dyadic 'is'? How could he then account for 'The man is running', and other such examples encountered in the last section? The following is a somewhat conjectural suggestion; the rest of the paper deals with the advantages of adopting it.

Two remarks in the De Interpretatione suggest that the monadic 'is' which attaches to simples such as nouns and verbs can be applied also to complex terms that involve a combination of simples. Thus: "Even 'goat- stag' signifies something but not as yet something true or false - unless 'is' or 'is not' are added" ( 16 b 16-18). And: "Even the logos of man is not yet a statement-making sentence, unless 'is' or 'will be' or 'was' or something else of that sort is added" (17 a 10-12). 
Appended to the second of these remarks is a significant comment. "To explain why two-footed land animal is a one not a many belongs to a different inquiry; certainly it is not by being said all together." When we look to one of the places where this "different inquiry" is conducted, Metaphysics Z 12, we find the following: "In the case of man and pale there is a plurality when one does not belong to the other, but a unity when it does belong and the subject, man, has a certain attribute; for then a unity is produced and we have the pale-man." (My hyphenation; 1037 b 14-17.) Aristotle then goes on to contrast this unity, the pale-man, with definitional unities such as two-footed land animal.

These remarks point to a certain correlativity between adjectives, including participles, in attributive and predicative positions. We are dealing now with a problem that arises when we see them in predicative position, namely that Aristotle does not seem to notice that the 'is' in such sentences is dyadic. But perhaps the reason that Aristotle does not make an explicit point of this is that

The man is running

can be transformed into the equivalent

The running man is.

Could Aristotle not be assuming, in other words, that all uses of 'is' corre- spond to a monadic use, and in particular that the copula can be rmiade monadic by moving its complement to attributive position?21 Such a monadic use of 'is' would be attached not to a noun or a verb but to a complex term. That monadic 'is' can be thus applied to complex terms is explicitly permitted by the De Interpretatione but the existence of dyadic 'is' is not.

Here then is a second account of Aristotle's theory of the subject- predicate sentence in the De Interpretatione.

(a) All subject-predicate sentences can be regarded as consisting of 'is' applied to a single term.

(b) The term to which 'is' is applied may be simple or complex. Examples of simple terms are 'man' or 'running'. A complex term consists of a noun 22 modified by a predicabledenoter in attributive position.

(a) and (b) need not be taken as grammatically analysing subject- predicate sentences, for obviously the latter include sentences with predi- cable-denoters in predicative position, and it would be a gross mistake to assimilate this syntactic pattern to the one that we are now discussing. Rather the claim is semantic: both the dyadic 'is' and the monadic 'is' provide semantic paradigms to which all subject-predicate sentences can be assimilated, however these sentences may be phrased.23 Aristotle sometimes uses one of these, sometimes the other, to make various points about ontology.

\section{PREDICATIVE COMPLEXES \\ III.I Introducing Predicative Complexes}

Let us now introduce the notion of a predicative complex - an entity formed, as Aristotle suggests in Metaphysics Z 12, from a universal and a particular when that particular 
instantiates that universal. (The predicative complex consisting of $\mathrm{x}$ and $\mathrm{F}$ does not exist when $x$ does not instantiate F.) The proposal in the first instance is that terms consisting of a substantive with an adjective in attributive position refer to such complexes when they refer to anything at all. For example, 'artistic Coriscus' will refer to a predicative complex when Coriscus is artistic, and to nothing otherwise.

It will be obvious that predicative complexes correspond rather closely to certain modern conceptions of facts, and to Russell's conception of a true proposition. There is however a difference: the modern conceptions I allude to are constructs out of individuals and properties, where properties are, like Frege's concepts, of a type distinct from the type of individuals. The Aristotelian conception that I am trying to reconstruct consists of individuals and predicables, where, because of the separation of 'is', the predicables are objects in Frege's sense of that term (universal objects, of course). A predicative complex is therefore the denotatum of a part of a sentence, and does not correspond to a sentence as a whole. An apt way to epitomize this difference is to note that the Russellian entity corresponding to 'Coriscus is artistic' could be referred to as 'Coriscus being artistic': the Aristotelian entity, on the other hand, is more properly called 'Coriscus- artistic' or 'artistic-Coriscus'. The point of Aristotle's remarks on 'is' as I understand them is that a complete thought is formed by attributing (monadic) being or non-being to one of these complexes, and that the complexes do not contain either of these as constituents.

The notion of a predicative complex enables us to explain the first comprehensiveness axiom:

$C$ 1: For all $x$ and $y$ there is a $z$ such that $x$ belongs to $y$ if and only if $z$ is without having to assume that the last 'is' that occurs in this principle (which is monadic and absolute) means anything other than 'exists'. This is because a predicative complex is a "unity" that exists only when one of its components instantiates the universal that is the other. Thus 'Simmias is large' is equivalent to 'Large Simmias is', and the latter is equivalent to 'Large Simmias exists'.

These equivalences mark significant advantages. The first of them makes sense of the attributive transformation noted earlier, and thus of the predicative-attributive dualities we noted earlier - the Platonic duality between saying that something is forever beautiful and saying that some beauty forever is, and the Aristotelian duality between the categories being "figures of predication" and kinds of things that are.

The equivalence of'Simmias is large' and 'Large Simmias exists' enables us to see why Parmenides and Plato (Sophist 237-241) thought that false and negative sentences are paradoxical. It is because negative sentences say that predicative complexes fail to exist, and false positive sentences pre- suppose reference to a non-existent predicative complex. Thus the problem of false and negative statements reduces to the problem of false and negative existentials. And we are able to achieve this reduction without resorting to the dubious technique of making truth fact-existence.

Our hypothesis helps make sense also of the occurrence of phrases like 'artistic Coriscus' and 'musical man' in the paragraphs on accidental oneness, being and sameness in Metaphysics $\Delta 6,7$ and 9 respectively. For it is plausible to interpret Aristotle as saying that where Coriscus is accidentally artistic, the artistic is accidentally 
the same as, and is accidentally one with, Coriscus, and that artistic Coriscus accidentally is. These theses (which I shall not work out in detail here) help make sense of the following sort of utterance:

Examples of accidental oneness are Coriscus and the artistic, and artistic Coriscus (for it is the same thing to say that Coriscus is one with the artistic and that artistic Coriscus is one). (Met, 1015 b 17-19)

Of particular interest to us is the correlation of the dyadic 'is one with' and the monadic 'is one' in the parenthetical remark, using precisely the device that I have called the attributive transformation. 24

\section{III.2 Does Aristotle Analyse Truth in Terms of Existence?}

It seems reasonable to suppose that if the notion of a predicative complex can account for the first, predicative, comprehensiveness axiom, then it could account for the second:

C2: For all propositions, $p$, there is an $x$ such that $p$ is true if and only if $x$ is.

This may well be the point of a much discussed passage in Metaphysics $\Delta$ :

'To be' and 'is' indicate also that something is true and 'not to be' that something is not true but false as is the case with affirmations and denials. For example, that Socrates is artistic (esti Sokrates mousikos), that this is true. (1017 a 31-35)

The traditional, and possibly most straight-forward, reading of these words is as saying that 'is' can mean 'is true'.

The crux is in the words 'That Socrates is artistic, that this is true' - to what does the 'this' refer? Presumably to the nearest truth-bearer: that Socrates is musical. But the 'is' in the nearest truth-bearer is not naturally taken as predicating anything of the whole sentence in which it occurs. So there is some difficulty in understanding the claim in the most straight- forward way. 25

I should therefore like to take Aristotle's words in a somewhat more oblique way, namely as claiming the equivalence of 'Artistic Socrates is' and 'That Socrates is artistic is true'. The point would then be that 'is' said-of predicative complexes indicates the same thing as 'is true' said-of the corresponding judgement.

This is to some extent confirmed by Metaphysics E 4 and e 10 wherein it is claimed that being as applied to composite objects is "combination and separation", which in turn parallels the claim made in Z 12 that a certain "unity", the pale-man, is brought into being when the man becomes pale, and the talk in the De Interpretatione about 'is' consignifying "combination and separation". Aristotle explicitly claims (1027 b $18 \mathrm{ff}$., $1051 \mathrm{~b}$ 33-35) that truth should be understood in terms of this being. And we have already noted that Aristotle defines truth and falsity in terms of an absolute 'is'. 
I propose therefore that Aristotle be taken not as saying that there is a use of 'is' that means 'is true'; just that truth, which is applied to pro- positions, can be analysed in terms of existence applied to another sort of thing.26

\section{III.3 Change}

Our conception of a predicative complex helps us understand how to take the notion of creation in a natural way - as the coming into existence of a thing - and still understand why, according to Aristotle explicitly, and according to Parmenides implicitly, every alteration is accompanied by an alteration. The trick is to regard every alteration as accompanied by the creation of one predicative complex, and by the destruction of another.

Obviously this will work only if a predicative complex like pale-Conscus is not identical with Coriscus; for it requires that pale-Coriscus cease to exist when Coriscus continues to exist. So our proposals demand that on at least one use of the term, 'pale Coriscus' be non-coreferential with 'Cor- iscus'. 27

There is confirmation of this at Theaetetus $159 \mathrm{~b}-160 \mathrm{~d}$. Here we find Socrates explaining, on Protagoras' behalf, that a draught of wine can seem sweet and pleasant to himself-in-health but bitter to himself-in-sickness. What is striking about this passage from our point of view is the use of the terms 'healthy Socrates' and 'sick Socrates' to refer to momentary objects. Since the term 'Socrates' would refer to an enduring object (whether or not Protagoras would acknowledge the existence of such objects) it seems that the terminology here presupposes that the term 'healthy Socrates' can, as our theory demands, be understood as non-coreferential with 'Socrates'. (Thus Protagoras might want to say something like 'Socrates does not exist, he is nothing, but healthySocrates exists momentarily', or 'Socrates is nothing but a construct out of components like the momentary healthy- Socrates'.)

An inspection of the passages just cited from the Theaetetus and earlier from Metaphysics $\Delta$ shows, by the way, that terms like 'a colour', 'a bitterness' and 'an artistic' (or, with appropriate ostensions, 'the artistic') are used as indefinite descriptions for things like the white-stick, the bitter-wine etc., that is for predicative complexes. (We noted earlier that Protagoras was willing to say things like 'A bitterness comes to be', and this could hardly be taken as announcing the creation either of e.g. wine, a substance, or of a universal.) We have shown that artistic Coriscus is not Coriscus. We can now supplement this with the indefinite identity: artistic Coriscus is an artistic (not a man). 28 This helps us to account for the indefinite transformation described which enables us to go from 'Cor- iscus/A man is/becomes artistic' to 'An artistic is/comes-tobe'. And, be- cause predicative complexes are individuals that are not substances, it also suggests that they might be the individuals out of which Aristotle con-structs categories other than substance.29

\section{III.4 The Expanded Ontology}


Predicative complexes constitute a third ontological realm distinct both from individual substances and from predicables. 30

Much of what Aristotle says about unities can be understood as making distinctions in the realm of these entities. Thus accidental unities are predicative complexes in which the predicable belongs only accidentally to the individual substance, and essential unities are those where this relation is essential - thus two-footed Coriscus would be an example of an essential unity.

An interesting possibility concerns a third kind of unity, which I shall call a definitional unity. An example of this would be matter-with-form, for instance an ensouled-body. This is not an essential unity because it is possible for the body to lack the soul - and after death it will. But Aristotle seems to want to hold that it is not simply an accidental unity either, because when an unity of this sort comes to be, a new substance comes to be. (The coming-to-be of a definitional unity is thus generation simpliciter.) It is possible, then, that Aristotle conceives of individual substances as themselves being predicative complexes, albeit of a special sort, inasmuch as they possess definitional unity. So if Aristotle is to distinguish between individual substances and other predicative complexes, which are not in the category of substance, it becomes important for him to distinguish definitional unity from merely accidental unity, and this is what he attempts to do in Metaphysics Z.

Some such notion of definitional unity is required to help us make sense of $D e A$ nima II, 1-2, in which Aristotle can be understood as implying the truth of a number of identities of the form 'A man is identical with a-body-with-certain-actualities'. The objection has been made to this that it implies that men are identical with bodies, which is false because bodies outlast men. The difficulty is solved by making men predicative complexes, and bodies components of these complexes. Obviously, this is plausible only if some predicative complexes are individual substances.

A similar move suggests an interpretation of Aristotle's representation of change. We saw earlier that Aristotle's refutation of the Parmenidean proof that there is no change cannot depend solely on the observation that alteration does not involve nonbeing. It is conceivable that Aristotle depends instead on the difference between the generation of complexes and the generation of simples; this is supported by his terminology, which distinguishes between genesis qualified and unqualified. If this is right, Aristotle would reject the generality of the Parmenidean principle that there is no creation or destruction, and accept it only in a restricted realm, namely simples. To justify this restriction would be a major task, but it would not be far-fetched to ground it on a correspondent restriction of the principle that negative existentials are logically faulty. Perhaps Aristotle wants to say that only those statements that deny the existence of simples are faulty. Perhaps this is in turn justified by observing that there is no difficulty in understanding what is asserted when we say that some combination of simples fails to exist provided that we know what the simples are, since this is equivalent to saying that the simples are not combined. If this is the right move, and if our proposal about individual substances being definitional unities composed of matter and form is accepted, then the way is open for Aristotle to represent the coming-to-be of individual substances as qualified, relative to the underlying matter. 
It is reasonable to identify accidental predicative complexes with immanent characters in the philosophy of Plato, and with non-substantial individuals in Aristotle. Plato insists (Phaedo $102 \mathrm{~d} 5 \mathrm{ff}$.) that in addition to the bearers of properties, like Simmias, and the properties they bear, such as largeness, there is a third class of entity exemplified by the largeness- in-Simmias. He also says that where Simmias admits the small, the large- ness-in-Simmias "retreats". This means that there is an equivalence between 'Simmias is large' and 'The largeness-in-Simmias exists' - and this supports the identification. Aristotle too seems to countenance such a class of entities: in Categories 2 he mentions items like the individual knowledge of grammar that are in but not saidof any subject.31

Gathering these suggestions together we should conclude that predicative complexes are referred to not only by phrases like 'the FX', but also by phrases such as 'the F-in-X', 'the $F$ of this $X$ ', ' $X$ 's F' and 'This F'. Of course some of these phrases might be ambiguous; and for instance 'the FX' might also be taken as referring to the underlying substance, and 'the $\mathrm{F}$ of this $\mathrm{X}$ ' might be taken as referring to a property.

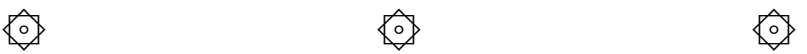

I have argued in this essay for the recognition of a sort of entity that is not familiar in modern ontologies. I have argued on the basis of a syntactic and semantic analysis of certain uses of 'is', and found textual support for the analysis in certain texts of Aristotle. In addition, the recognition of predicative complexes enables us to give a unified treatment of a number of puzzling features of Greek ontology.

It is possible that the Greeks may have regarded predicative complexes not in the way I have presented them, namely as constructed entities derivative from more basic types, but as the entities given in perception, and so epistemically and even ontologically prior. If so, we may find that in positing the Forms, Plato was making a break with an ontology of predicative complexes, not, as is usually thought, with an ontology of individual substances. Similarly, it is possible that Aristotle posited individual substances against the background of an ontology composed of predicative complexes and Platonic Forms. These possibilities offer the prospect of a richer appreciation of the development of Greek ontology than is now customary.32

McGill University 


\section{NOTES}

1The statement of non-contradiction with absolute 'to be' is implied at Metaphysics $\Gamma 1005 \mathrm{~b} 24$ and 1006 a 1, and occurs explicitly at 1006 a 4 . The juxtaposition of these statements with the longer, predicatively phrased statement at $1005 \mathrm{~b} 18$ shows that no distinction is intended between the two ways of stating the principle.

2 The incomplete copula is an apparently absolute use of 'is' that is actually elliptical for some copulative use. An uncontroversial example would be: 'Is Tom well-dressed? Yes, he is.' I very much doubt that one could justify a rule of grammar that permits predicate-deletion except in such cases of repetition, and so I suspect that the theory of the incomplete copula is grammatically ad hoc. Fortunately, the theory that I will present here renders this item unnecessary.

3 A similar point is made in M. F. Burnyeat (ed.) Notes on Metaphysics Z (Oxford: The SubFaculty of Philosophy, 1980). The use of 'is' at 1028 a 18 is said not to be the incomplete copula on the grounds that it predicates existence of certain universals. (Actually, the interpretation to be advanced here will imply agreement with the assessment that this is an 'is' of existence, but not that its subject is a universal.)

4 Charles Kahn, "Some Philosophical Uses of'to be' in Plato", Phronesis XXVI (1981), see especially pp. 107-109.

5 It seems to me that Protagoras would have been prepared to say also that something is $F$ whenever an $\mathrm{F}$ is, were it not for the fact that the durative implications of 'is' are inconsistent with his endorsement of Heraclitean flux (as Plato portrays him in the dialogue, 160 ae). But whether this is true or not, it is generally true that facts about the durative copula, 'is', are paralleled by facts about the mutative copula, 'becomes'.

6 It is, I think, significant that the Categories 4 list of things-that-are includes items that are predicated.

7 Thus suppose that $\mathrm{C} I$ is true. Let $\mathrm{C}$ be an entity that is if and only if $\mathrm{A}$ belongs to $\mathrm{B}$. (There is such an entity; $\mathrm{Cl}$ ensures this.) Then if, per impossibile, $\mathrm{A}$ both belonged and did not belong to $\mathrm{B}$, $\mathrm{C}$ would both be and not be (and conversely). Thus $\mathrm{CI}$ implies that $\mathrm{O}$ and $\mathrm{P}$ are equivalent. Again suppose that $\mathrm{Cl}$ does not hold. Then there would be an individual that both was and was not without some $x$ belonging to some $y$, and conversely.

Thus the falsity of $\mathrm{CI}$ implies that $\mathrm{O}$ and $\mathrm{P}$ are not equivalent. Thus $\mathrm{CI}$ if and only if $\mathrm{O}$ and $\mathrm{P}$ are equivalent.

8 See Montgomery Furth, "Elements of Eleatic Ontology", Journal of the History of Philosophy 6 (1968).

9 Kahn's theory is stated in several articles and a book. Of these the most useful from a synoptic point of view are the first and the most recent: "The Greek Verb 'To Be' and the Concept of Being", Foundations of Language 2 (1966), and the article cited in note 4, above.

10 David Wiggins, "Sentence Meaning, Negation and Plato's Problem of Non-Being", in G. Vlastos (ed.), Plato 1, (Garden City N.Y.: Anchor Books, 1971).

11 See his "Why Existence does not Emerge as a Distinct Concept in Greek Philosophy", Archivfur Geschichte der Philosophie 58 (1976), esp. pp. 326-7. The argument I give is mine; Kahn relies on a type-distinction between existence and being-so. The trouble with Kahn's argument, as I see it, is that it does not prevent being-so being what corresponds to existence in this other type, with all the logical properties that Wiggins wants. Another argument with a conclusion similar to Kahn's but based on the questionable assumption that one and the same event can recur, is found in Roderick Chisholm, "Events and Propositions", Nous 4 (1970). 
For a sophisticated representation of events and the notion of occurrence easily extendible to facts and being-so, see Richard Montague, "On The Nature of Certain Philosophical Entities", in R. H. Thomason (ed.), Formal Philosophy: Selected Papers of Richard Montague (New Haven and London: Yale University Press, 1974), especially pp. 148-150. 12 Charles Kahn, "The Thesis of Parmenides", The Review of Metaphysics XXII (1969). "Parmenides is concerned with knowledge in the sense in which it implies Truth ... The 'is' which Parmenides proclaims is not primarily existential but veridical" (p. 712). Thus the objects of knowledge must be, i.e. must be true.

13 It is, I think, a significant feature of the construction that Kahn calls "the veridical construction proper" that it never allows 'is' to attach directly to a sentence or sentence nominalization. Rather a verb of thinking or saying is required: 'Things are as you say' etc. (There are idiomatic exceptions to this rule: 'These things are' is a formula of assent in Greek, and 'So be it' is allowed in English as well as Greek.) Some explanation is required of this difference with 'is true'.

14 It is unclear where this leaves adjectives such as 'white' and common nouns such as 'man' these do not carry tense but they do signify-about, that is they are used in predicate position. Perhaps signifying-about is supposed to be compatible with signifying (cf. Met, 1006 b 14-15). I shall make a suggestion about adjectives in due course.

15 Is the suggestion that 'white' is a verb? But it lacks tense.

16 The theory that I am attributing to Aristotle is similar to the one held by Peter Abelard. Abelard raises the problem of 'the running man' and solves it in the way outlined here, and he introduces explicitly the notion of the copula-equivalent; he calls this the vis copulativa. See Martin M. Tweedale, "Abelard and the culmination of the old logic", chapter 6 of Norman Kretzmann, Anthony Kenny, Jan Pinborg (ed.), The Cambridge History of Later Medieval Philosophy, (Cambridge: Cambridge University Press, 1982), especially pp 143-148. My point is that most of the ingredients of Abelard's account are latent in Aristotle's, and that they are required to make sense of what Aristotle says.

For a further interesting account of some of the problems discussed here, see J. M. E. Moravcsik, "Aristotle's Theory of Catogories", in his Aristotle (Garden City, N. Y.: 132 Anchor Books, 1967), pp 129-132. It would seem that Moravcsik's innocent looking remark on $p$. 129 , that Aristotle "treats 'being' as a verb" creates difficulties in Moravcsik's discussion. We have seen that this claim ought to be qualified.

17 This recalls Abelard's point that there is little difference between adjoining 'is' to a noun and adjoining it to adjectives or participles. Both procedures yield a verb-phrase. Why do Plato and Aristotle distinguish in so sharp a way between common nouns and predicable-denoters? For one answer to this question, see J. M. E. Moravcsik, "The Discernibility of Identicals", Journal of Philosophy, LXXIII (1976).

18 Some authors have thought that Aristotle thinks of the sub-structure of the declarative sentence in much the same way as Plato does in the Sophist. They thus distinguish this theory from that of the early Plato who, according to them, thought of predicates as names of universals, a tendency that leads to the theory of transcendent forms. I have in mind particularly G. B. Matthews and S. Marc Cohen, "The One and the Many" Review of Metaphysics 21 (196768), and Joan Kung, "Aristotle on Thises, Suches and the Third Man Argument", Phronesis XXVI (1981). These authors attribute to Aristotle the insight that predicates are not names, and try to found the priority of substances over non-sub- stances on the difference in logical type or function between these two categories of expression. I believe that the De Interpretatione passages discussed herein throw some doubt on the usefulness of this approach because they show that the insight attributed to Aristotle is compatible with there being names for items in 
the non-substantial categories. For further discussion of the implications of this point see my

"Aristotle's Semantics and a Puzzle Concerning Change", forthcoming in 1984 in a supplementary volume of the Canadian Journal of Philosophy devoted to articles on Aristotle. 19 Kahn is certainly aware that there are type-difficulties in his conception of the 'is' of truth: see his review of Jonathan Barnes, The Presocratic Philosophers, in the Journal of Philosophy LXVIII (1981). See also note 11 above. My point here is that Aristotle's ciarity on type questions in the De Interpretatione makes it unlikely that any type-confusion can be attributed to him. 20 It might be doubted that 'Running is' is a legitimate Greek sentence, but see the results of what I have called the "'indefinite transformation" in section 1.4 above. Note also that predicable-denoters occur in the list of onta in Categories 4 . This participle embodies an absolute use of 'is'.

21 The remarks made in the last section about separating the predicable-denoting from the sentence-completing functions continue, of course, to have force in this new representation. We can thus understand Aristotle's comment at De Int 16 b 19, "When uttered by itself a verb is a noun and signifies something.. . but it does not signify whether it is or not". and the remarks at 16 a 12-19, as a pointed rejection of Plato's view (Sophist 26 le) that nouns and verbs are "two sorts of revealers of being". The separation of the copula would not permit this by itself since the counterpoised opinions are clearly stated in terms of monadic 'is'.

The separation of the sentence-completing function and the identification of this with monadic 'is' also throws some light on Aristotle's characteristic doctrine that Being is not a genus. Genera are denoted by predicable-denoters; 'is' does not denote a predicable. The failure to understand this point can lead to the misplaced expenditure of philo- sophical effort on explaining the lack of "cognitive content" of Being or existence to explain Aristotle's views: see Joseph Owens, "The Content of Existence", in Milton Munitz (ed.), Logic and Ontology (New York: New York University Press, 1973). Owens correctly treats 'exists' as grammatically a predicate, but seems to assume that therefore it must be semantically similar to other predicates. Put in these terms, the problem becomes to account for the Aristotelian doctrine about Being not being a genus without the help of the Aristotelian account of'is' not being a predicable-denoter.

22 In Greek it is permissible to construct a noun-phrase without the use of a noun - for example 'hoi en agora' means 'the men in the agora'. I am not sure whether this requires a broadening of the definition of 'complex term', because Aristotle may well want to assert that nouns are implicitly present in such phrases - "optionally deleted" as we should say - a doctrine that is made highly plausible by the requirement that the article in such phrases agree in gender with the approprate noun. (It is this requirement that enables us to tell that the phrase 'hoi en agora' refers to men.)

23 I am being cautious here: I want to distingush both syntactically and semantically between ' $x$ is $F$ ' and $F x$ is'. I think that given the existence of whatever is denoted by ' $F x$ ', ' $F$ ' and ' $a$ ', the two sentences are equivalent but have different "sense and reference". A parallel example would be the pair 'The snow is white' and 'That the snow is white is true'. Given the existence of both the snow and the proposition that snow is white, the two statements are equivalent; but whereas the second makes a claim about the first pro- position, the first makes a claim about the snow. My claim, elaborated in 111.2, is that Aristotle sometimes explains the truth conditions of dyadic 'is' sentences in terms of monadic 'is' sentences, not that he ignores or eliminates the former. In this respect his efforts are comparable to Tarski's, who explained the truth conditions of sentences containing 'true' in terms of sentences not containing 'true'.

24 Commentators have been baffled by this and thus they have not always understood this passage in accordance with the smoothest reading of the Greek - see Christopher Kirwan's lucid 
discussion of the controversies surrounding these lines in his commentary, Aristotle's

Metaphysics Books $\Gamma, \Delta$, E (Oxford: The Clarendon Press, 1971).

Note, however, Kirwan's remark that "the artistic Coriscus is a unified complex in which Coriscus - somehow detached from his artistry - is a simple part" (134). It seems that Kirwan's awareness of the implications of his own suggestion that artistic Coriscus is a complex is not sufficiently explicit. Coriscus is distinct from the artistic Coriscus simply because he is a proper part of the latter - there is no need to detach him from his artistry to secure the result.

25 Kirwan makes this point well in his commentary, op. cit.

26 Points similar to those made in this section are to be found also in an unpublished paper by John Thorpe, "Aristotle on Being and Truth", read at the meetings of the Canadian Philosophical Association held in Ottawa, June 1982.

27 Not realizing that there is this use of phrases like 'pale Coriscus', C. J. F. Williams, in Aristotle's De Generatione et Corruptione (Oxford: The Clarendon Press, 1982), says that 319 b $20 \mathrm{ff}$. (discussed above) "requires an incoherent understanding of'An unmusical man came into existence' since it has to forbid the inference to 'A man came into existence'." The same cause accounts for the textual transposition made by Philoponus and Joachim at $319 \mathrm{~b} \mathrm{28-20}$. See H. H. Joachim Aristotle on Coming to Be and Passing Away (Oxford: The Clarendon Press, 1922), p. 109. Left where it is in the manuscripts, the offending sentence says that the musical-man and the unmusical-man are affections (pathe) of what underlies.

28 These indefinite descriptions are used in the Physics to identify aitiai, and it is possible that properly speaking, aitiai are predicative complexes. This would account for the apparent intensionality of aitiative contexts noted by J. M. E. Moravcsik in "Aristotle on Adequate Explanation" in Synthiese 28 (1974). On the other hand the relation of 'accidental sameness" i.e. the relation that holds of a pair of predicative complexes or a predicative complex and an individual substance when the individual substances in question are identical - makes it possible to account for the apparent extensionality of aitiative contexts noted by James Bogen in his comment on Moravcsik's paper, provo- catively titled "Moravcsik on Explanation", loc. cit. 29 Let us distinguish between two forms of words, ' $X$ is $Y$ ' and ' $X$ is a $Y$ '. These have been thought to be forms of predication, the first accounting for cross-categorial predication and the second for intra-categorial predication. I am more inclined to think that' $X$ is a $Y^{\prime}$ is in fact not predicative at all, but expresses an identity statement, in which one of the terms is expressed indefinitely. These identities can be used to make the scheme of categories hierarchically consistent in the following way. Suppose that $x$ is an $F$ and $y$ is a G, and suppose that we have grounds for supposing either that the individuals or the predicables belong to different categories. Then we put the other term into different categories as well. This procedure would of course not be available in the case of predication as normally understood. The difference is that whereas something can have properties in different categories, it cannot be identical with things in different categories.

30 When this fact is not taken into account, Aristotle's odd-sounding pronouncements on the subject of accidental sameness (see 111.1) can be interpreted as incorporating non- standard or confused views on identity: see Nicholas P. White, "Aristotle on Sameness and Oneness", The Philosophical Review LXXX (1971), and "Origins of Aristotelian Essentialism", The Review of Metaphysics XXVI (1972-73), Alan Code, "Aristotle's Responses to Quine's Objections to Modal Logic", Journal of Philosophical Logic 5 (1976), and S. Marc Cohen, "Essentialism in Aristotle", The Review of Metaphysics XXXI (1977-78).

31 A longer catalogue of Aristotelian texts committed to the existence of such entities will be found in Robert Heinaman, "Non-Substantial Individuals in the Categories". Phronesis XXVI (1981), especially pp. 295-7. 
32 An ancestor of a fragment of this paper was presented to the Canadian Philosophical Association in Halifax, June 1980 and was acutely commented on by David Hitchcock. A complete draft was criticized in detail by Charles Kahn. Both these philosophers not only saved me from error but made a large number of useful positive suggestions. Alastair McKinnon made it possible to process the final version on McGill University's computer. 